Review

\title{
Inclusion of Tomato in the Genus Solanum as "Solanum lycopersicum" is Evident from Phylogenetic Studies
}

\author{
Erika Asamizu and Hiroshi Ezura* \\ Graduate School of Life and Environmental Sciences, University of Tsukuba, Ibaraki 305-8572, Japan
}

\begin{abstract}
As DNA sequence data were rapidly accumulated in the last decade, the intense debate on the position of the genus "Lycopersicon" with respect to "Solanum" was recently settled. In this review, we focus on chloroplast DNA restriction fragment length polymorphism (cpRFLP) analysis and molecular phylogenetic study of the chloroplast-encoded NADH dehydrogenase $(n d h F)$ gene of numerous Solanaceae family members including tomato, Solanum lycopersicum (formerly Lycopersicon esculentum). Both studies revealed that S. lycopersicum is clearly included in the large genus Solanum, which includes potato (S. tuberosum) and eggplant (S. melongena). All cpRFLP and different algorithms in $n d h F$ phylogenetic analysis classified $S$. lycopersicum into the same clade as $\boldsymbol{S}$. tuberosum. Comparative genome analysis using a high-density genetic linkage map of $S$. lycopersicum and S. tuberosum indicated that the chromosome structure is highly conserved between the two species. These recent studies indicated that tomato and potato are phylogenetically close and share a recent common ancestor.
\end{abstract}

Key Words: genus Solanum, phylogeny, scientific name, Solanum lycopersicum, tomato.

\section{Introduction}

The first Solanaceae family species introduced in Japan was eggplant, more than 800 years ago in the Heian period. Since then, numerous original eggplant cultivars have been bred in various parts of the country and are a popular vegetable in Japanese food. Because of the popularity of eggplant, "nasuka", which means "family related to eggplant", is the Japanese word for the Solanaceae family. On the other hand, tomato has become a popular Japanese food relatively recently. Although it was introduced in Japan about 300 years ago in the Edo period, it was esteemed as an ornamental plant until generally adapted as food in the last century.

In the academic world, tomato has long been distinguished from the genus Solanum, which includes eggplant (Solanum melongena) and potato (Solanum tuberosum) as well as 1400 other species, and classified in an original genus Lycopersicon. The scientific name Lycopersicon esculentum was given to tomato in the 1760 s by a Scottish botanist Philip Miller, and the name has been widely accepted since then. Readers should refer to a well-summarized historical debate on the Solanaceae phylogenetic relationship by Spooner et al. (1993).

Received; July 30, 2008. Accepted; October 3, 2008.

* Corresponding author (E-mail: ezura@gene.tsukuba.ac.jp).
As a fruit of rapid progress in DNA sequencing technology in the 1990s, a large amount of DNA sequence data has been produced and accumulated in public databases. In the last decade, molecular phylogenetic analyses were accelerated using sequence data. The obtained results suggested that it is necessary to reclassify the plant kingdom. In this article, we review the reclassification of the genus Solanum with special emphasis on molecular phylogenetic studies at the DNA level, and conclude that the inclusion of tomato "Solanum lycopersicum" is quite persuasive.

\section{Phylogenetic analysis of chloroplast DNA restriction sites}

Olmstead and Palmer (1992) investigated the phylogeny of Solanaceae based on chloroplast DNA restriction site mapping. They took 42 species of Solanaceae and digested the chloroplast DNA with each of 10 restriction enzymes. Among the 1,000 fragments generated, 447 gave phylogenetically informative data. They performed restriction fragment length polymorphism (RFLP) analysis using 40 hybridization probes developed from Nicotiana tabacum chloroplast DNA, which had been completely sequenced (Shinozaki et al., 1986). They then mapped 14 restriction-fragment length variants representing insertions and deletions ranging in size from 150 to 700 base pairs. According to the result, 
Solaneae including Capsicum, Solanum candidum, S. carolinense, S. luteoalbum, S. americanum, and Lycopersicon, was monophyletic and was derived from an ancestral paraphyletic Cestroideae which includes Nicotiana and Petunia. The tree indicated that Lycopersicon was grouped into the same clade as other Solanums.

Spooner et al. (1993) also performed chloroplast RFLP analysis to test hypothetical relationships among Solanum subgenus Potatoe, Cyphomandra (tree-tomato), and Lycopersicon. As a result of analysis using 17 accessions of Solanum subgenus Potatoe, four other Solanum, three Lycopersicon, one Cyphomandra, and one each for Capsicum and Datura as the outgroup, they concluded that Lycopersicon should be treated as a member of the genus Solanum, subgenus Potatoe. They also provided supportive results for the inclusion of Cyphomandra in Solanum.

Olmstead and Palmer (1997) refined their work using the same methodology to investigate the detailed infrageneric phylogeny of subgenera, including Lycopersicon and Cyphomandra (tree-tomato). They took 49 species, of which 36 were Solanum and 13 were outgroup species. They showed that Solanum, including Lycopersicon and Cyphomandra formerly designated as distinctive genera, are monophyletic. The result indicated that Solanum could be divided into 3 clades: Clade I, consisting of S. aviculare, S. ptychanthum (revised from $S$. americanum in the previous work of Olmstead and Palmer, 1992), S.crispum, S.dulcamara and S.jasminoides; Clade II, consisting of S. lycopersicum, $S$. tuberosum and S. muricatum; Clade III, consisting of the remaining sampled members of the genus including S. luteoalbum (Cyphomandra) (Fig. 1). The result suggested that Lycopersicon and Cyphomandra should be treated as a clade within the genus Solanum rather than as a distinctive genus.

\section{Phylogenetic analysis based on $n d h F$ sequences}

It was previously demonstrated that NADH dehydrogenase $(n d h F)$ encoded in the chloroplast genome is suitable for inferring the phylogenetic relationship at intra-familial level because of the elevated rate of base substitution in its nucleotide sequence compared to the ribulose bisphosphate carboxylase $(r b c L)$ gene accepted widely in large-scale phylogenetic analyses at the interfamilial level (Olmstead and Palmer, 1994; Savolainen and Chase, 2003). Bohs and Olmstead (1997) used 2000 base pairs of the $n d h F$ sequence to analyze the phylogenetic relationship of Solanum. They sequenced

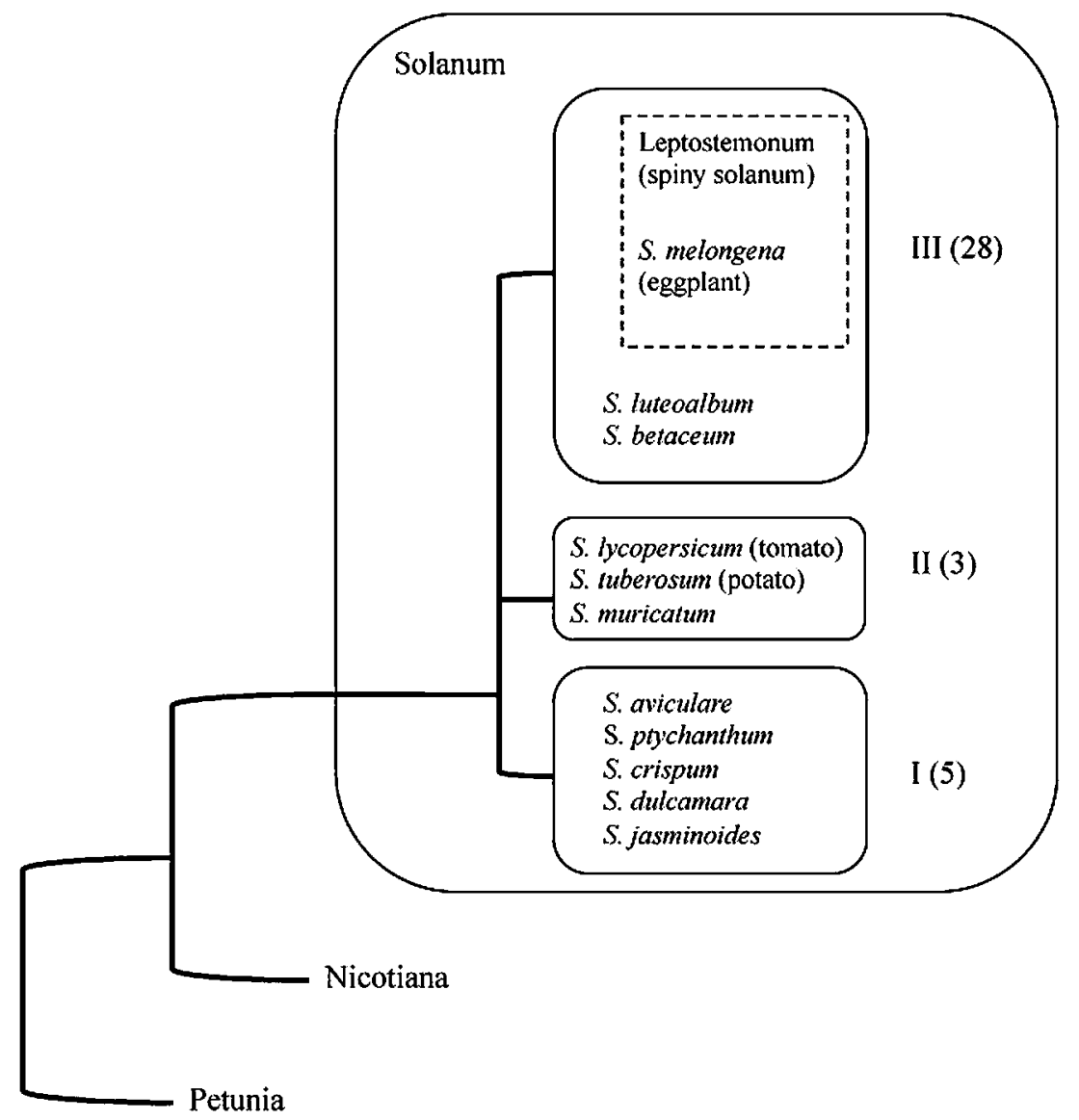

Fig. 1. Schematic view of the Solanum tree modified from Olmstead and Palmer (1997). Solanum was divided into 3 clades. S. lycopersicum was grouped into clade II with S. tuberosum and S. muricatum. Clade III included tree-tomato species e.g. S. luteoalbum and S. betaceum, as well as 19 spiny solanums such as S. melongena, which were classified into the subgenus Leptostemonum. 
the $n d h F$ gene for 18 species of Solanum for which the sampled species were generally common with those used in the chloroplast DNA RFLP (cpRFLP) study (Olmstead and Palmer, 1997). Results of two different algorithms, parsimony and maximum likelihood analyses, indicated that the genera Lycopersicon (as S. lycopersicum) and Cyphomandra (as S. betaceum) are nested within Solanum and inclusion of these two species supported the monophyletic feature of Solanum. Solanum was distinguished by 4 clades in this analysis, where S. lycopersicum and S. tuberosum were classified in the same clade, which included no other species. Readers are encouraged to see the phylogenetic tree produced by grafting cpRFLP (Olmstead and Palmer, 1997) and $n d h F$ (Bohs and Olmstead, 1997) histories in a review article by Kellogg (1998).

\section{Conclusion}

The position of the genus formerly known as Lycopersicon relative to Solanum has been a longstanding question, which was solved only recently by utilizing DNA structural information since it may provide direct evidence of molecular evolution. This review focused on phylogenetic studies based on cpRFLP (Olmstead and Palmer, 1992; Olmstead and Palmer, 1997) and $n d h F$ sequence (Bohs and Olmstead, 1997). Alternative researches also support the idea that Solanum is monophyletic. High-density genetic linkage maps of tomato (S. lycopersicum), potato (S. tuberosum), and eggplant (S. melongena) were generated (Doganlar et al., 2002; Tanksley et al., 1992) and comparison of the chromosome structure based on a common set of DNA markers was made. The result indicated that the chromosome organization of tomato and potato could be distinguished by only 5 rearrangements resulting in chromosome arm inversions. This strikingly similar chromosome organization indicates that they share a recent common ancestor. In the case of comparison between tomato/eggplant and potato/eggplant, 28 and 24 rearrangements were observed, respectively. It was also indicated that these 3 Solanum genomes were largely collinear.
Tomato is recognized as a model organism of Solanaceae and its entire euchromatic genome is being sequenced (http://www.sgn.cornell.edu/about/tomato sequencing.pl, October 2, 2008). In the near future, an interesting challenge to elucidate evolutionary history of Solanum on a genome-wide scale should become a reality.

\section{Literature Cited}

Bohs, L. and R. G. Olmstead. 1997. Phylogenetic relationships in Solanum (Solanaceae) based on ndhF sequences. Syst. Bot. 22: 5-17.

Doganlar, S., A. Frary, M. C. Daunay, R. N. Lester and S. D. Tanksley. 2002. Conservation of gene function in the Solanaceae as revealed by comparative mapping of domestication traits in eggplant. Genetics 161: 1713-1726.

Kellogg, E. A. 1998. Who's related to whom? Recent results from molecular systematic studies. Cur. Opin. Plant Biol. 1: 149158.

Olmstead, R. G. and J. D. Palmer. 1992. A chloroplast DNA phylogeny of the Solanaceae: Subfamilial relationships and character evolution. Ann. Missouri Bot. Gard. 79: 346-360.

Olmstead, R. G. and J. D. Palmer. 1994. Chloroplast DNA systematics: a review of methods and data analysis. Am. J. Bot. 81: 1205-1224.

Olmstead, R. G. and J. D. Palmer. 1997. Implications for the phylogeny, classification, and biogeography of Solanum from cpDNA restriction site variation. Syst. Bot. 22: 19-29.

Savolainen, V. and M. W. Chase. 2003. A decade of progress in plant molecular phylogenetics. Trends Genet. 19: 717-724.

Shinozaki, K., M. Ohme, M. Tanaka, T. Wakasugi, N. Hayashida, T. Matsubayashi, N. Zaita, J. Chunwongse, J. Obokata, K. Yamaguchi-Shinozaki, C. Ohto, K. Torazawa, B. Y. Meng, M. Sugita, H. Deno, T. Kamogashira, K. Yamada, J. Kusuda, F. Takaiwa, A. Kato, N. Tohdoh, H. Shimada and M. Sugiura. 1986. The complete nucleotide sequence of the tobacco chloroplast genome: its gene organization and expression. EMBO J. 5: 2043-2049.

Spooner, D. M., G. J. Anderson and R. K. Jansen. 1993. Chloroplast DNA evidence for the interrelationships of tomatoes, potatoes, and pepinos (Solanaceae). Am. J. Bot. 80: 676-688.

Tanksley, S. D., M. W. Ganal, J. P. Prince, M. C. de-Vicente, M. W. Bonierbale, P. Broun, T. M. Fulton, J. J. Giovannoni, S. Grandillo, G. B. Martin, R. Messeguer, J. C. Miller, L. Miller, A. H. Paterson, O. Pineda, M. S. Roder, R. A. Wing, W. Wu and N. D. Young. 1992. High density molecular linkage maps of the tomato and potato genomes. Genetics 132: 1141-1160. 